\title{
Deficient Collagen-Induced Activation in the Newborn Platelet
}

\author{
SARA J. ISRAELS, MICHELE DANIELS, AND EILEEN M. MCMILLAN \\ Manitoba Institute of Cell Biology and the Department of Pediatrics, University of Manitoba, \\ Winnipeg, Manitoba, Canada
}

\begin{abstract}
We have investigated the impaired secretion response of neonatal platelets. We compared the response of washed neonatal and adult platelets to thrombin and collagen, and to specific activators of calcium flux (inositol trisphosphate) and protein kinase $\mathrm{C}$ activation (oleoylacetyl glycerol). Neonatal platelets show no impairment of aggregation, secretion of $\left[{ }^{14} \mathrm{C}\right]$ serotonin or phosphorylation of specific intracellular proteins in response to thrombin, inositol trisphosphate, or oleoyl-acetyl glycerol. However, neonatal platelets have a markedly decreased response to collagen. To further evaluate this deficient response, we examined specific aspects of the collagen activation pathway. Collagen-platelet interaction as measured by adhesion of platelets to collagen-coated dishes showed no difference in adhesion of neonatal platelets compared to adult controls $(20.1 \pm 11.6$ versus $18.6 \pm 9.3 \%)$. The presence of GPIa/ $\mathrm{IIa}, \mathrm{a} \mathrm{Mg}^{2+}$-dependent collagen receptor, was evaluated by flow cytometric analysis of binding of fluorescein-tagged monoclonal antibody, 6F1 (directed against GPIa/IIa). There was no difference either in the percent of platelets that bound antibody ( 80 versus $81 \%$ ) or in the mean fluorescence intensity of the adult and neonatal samples. Phosphoinositide hydrolysis was decreased in neonatal platelets in response to collagen but normal in response to thrombin. Neonatal platelets released more arachidonic acid than adult platelets in response to thrombin $(29.5 \pm 3.2$ versus $19.6 \pm 1.8 \%$ ) but less than adult platelets in response to $10 \mu \mathrm{g} / \mathrm{mL}$ collagen $(3.2 \pm 1.1$ versus $9.3 \pm 3.0 \%)$. Thromboxane $\mathrm{B}_{2}$ production was also decreased in response to collagen $(52.7 \pm 12.6$ versus $101.4 \pm 18.7 \mathrm{ng} / \mathrm{mL})$. These results suggest that the deficient collagen response in neonatal platelets may lie in transduction of the collagen signal to phospholipases $A_{2}$ and C. (Pediatr Res 27: 337343,1990 )
\end{abstract}

$\quad$ Abbreviations
AA, arachidonic acid
IP $_{3}$, inositol-1,4,5-trisphosphate
OAG, oleoyl-acetyl glycerol
PIP $_{2}$, phosphatidylinositol-4,5-bisphosphate
MLC, myosin light chain
$47 \mathrm{~K}, 47000$ dalton protein
TxA $_{2}$, thromboxane $\mathrm{A}_{2}$
TxB $_{2}$, thromboxane $\mathrm{B}_{2}$
HBSS, Hanks' balanced salt solution

The transient physiologic alterations in the neonatal hemostatic system have been of interest for many years, and of major

Received May 30, 1989; accepted November 27, 1989.

Received Biology, 100 Olivia Street, Winnipeg, Mannitoba, R3E OV9, Canada.

Supported by grants from the Manitoba Medical Services Foundation and the Children's Hospital of Winnipeg Research Foundation. clinical importance to those caring for sick and premature infants. The differences in clotting factor activity and fibrinolytic enzymes between cord blood and that of adult controls are well established $(1,2)$. The abnormalities of neonatal platelet function are less completely understood. In the mid-1970s, differences in the in vitro responses of cord and newborn platelets compared to those from older subjects were identified (3-6). These abnormalities include a decreased aggregation response to certain agonists including ADP, epinephrine and collagen $(3,4)$, and decreased secretion of dense granule contents $(5,6)$. Neonatal platelets were shown to have decreased endogenous stores of dense granule contents, ADP, and serotonin, although Whaun demonstrated that their uptake and storage of radiolabeled serotonin was as effective as that of adult platelets (6). In addition, electron microscopy has not revealed a difference in the number or structure of these granules in neonatal platelets (7).

Granule secretion is necessary for irreversible aggregation of platelets as it potentiates the primary aggregatory response produced by an external stimulus. Platelets with either absent granule contents $(8)$ or a defect in the release mechanism $(9,10)$ show abnormal responses in vitro and are the cause of clinical bleeding syndromes. Therefore, we began our investigations of neonatal platelet function by reexamining the secretion response. As in previous studies, we observed decreased secretion, which was most pronounced in response to collagen. We proceeded to study specific aspects of the activation pathway leading to secretion, including those uniquely involved in the response to collagen, to identify the defect in the neonatal platelet response to collagen.

\section{MATERIALS AND METHODS}

Blood collection and preparation. Cord blood was collected from the umbilical vein, immediately after clamping of the cord. Samples were obtained from elective cesarean births in which both neonate and mother were in good health and the mother was not taking medication. Cord blood was drawn into plastic syringes containing citrate/citric acid/dextrose anticoagulant. Adult blood was obtained by venipuncture into the same anticoagulant from adult volunteers with no history of bleeding diathesis or drug ingestion. In each case, platelet rich plasma was prepared by centrifugation of the citrated whole blood at $200 \times$ $g$ for $20 \mathrm{~min}$ at $20^{\circ} \mathrm{C}$. Platelet counts were done using a Coulter counter model ZB1 (Coulter Electronics, Hialeah, FL). Platelets were then washed (11) and resuspended in buffer appropriate for the particular study.

Preparation of collagen. Acid soluble collagen was prepared by homogenizing calf skin collagen (type I) with $6 \%$ acetic acid. The supernatant and gelatinous precipitate were diluted and centrifuged at $1000 \times g$ for $20 \mathrm{~min}$ (12). Before use as monomeric collagen the preparation was dialyzed against $0.05 \%$ acetic acid.

Aggregation studies. Aggregation was studied using a Payton dual channel aggregometer (Payton Associates, Scarborough, 
Ontario) at $37^{\circ} \mathrm{C}$ under stirring conditions. Platelets were suspended in a Krebs-Ringer's-HEPES buffer $(120 \mathrm{mM} \mathrm{NaCl}, 4.7$ $\mathrm{mM} \mathrm{KCl}, 1.2 \mathrm{mM} \mathrm{KH} \mathrm{PO}_{4}, 1.2 \mathrm{mM} \mathrm{MgCl}_{2}, 10 \mathrm{mM}$ HEPES, $15 \mathrm{mM}$ dextrose, $0.2 \%$ albumin) $\mathrm{pH} 7.4$ (13), for the study of all agonists except $\mathrm{IP}_{3}$. For agonists other than $\mathrm{IP}_{3}, 1 \mathrm{mM} \mathrm{CaCl}$ was added to each sample 2 min before the addition of agonist. The agonists used were $0.2 \mathrm{U} / \mathrm{mL}$ thrombin, $1.0 \mu \mathrm{g} / \mathrm{mL}$, and 10 $\mu \mathrm{g} / \mathrm{mL}$ bovine collagen, $100 \mu \mathrm{g} / \mathrm{mL} \mathrm{OAG}$, and the calcium ionophore, A23187 $(4.0 \mu \mathrm{M})$. The platelet response to $\mathrm{IP}_{3}$ was monitored as previously described (14). In brief, platelets were resuspended in a high potassium buffer with $40 \mu \mathrm{M}$ EGTA to chelate any external calcium and permeabilized using saponin $(12 \mu \mathrm{g} / \mathrm{mL})$ to permit entry of $\mathrm{IP}_{3}(5-10 \mu \mathrm{M})$ into the cell. Maximum aggregation was recorded at $5 \mathrm{~min}$ after addition of the agonist.

Secretion of serotonin from platelet-dense granules. Platelets labeled with $1.0 \mu \mathrm{Ci} / \mathrm{mL}$ of $\left[{ }^{14} \mathrm{C}\right]$ serotonin were studied by the method of Jerushalmy and Zucker (15). Platelet samples were stimulated in the aggregometer with agonists, as described above, and allowed to aggregate for $2 \mathrm{~min}$ before the response was halted with an equal volume of $0.1 \%$ glutaraldehyde. These samples were centrifuged at $2000 \times g$ for $10 \mathrm{~min}$ to pellet the platelets. Percent release was calculated by comparing radioactivity in the supernatants of stimulated samples to that of unstimulated controls.

Protein phosphorylation studies. Phosphorylation of MLC and $47 \mathrm{~K}$ were studied as previously described (16). In brief, $1.0 \mathrm{mCi} /$ $\mathrm{mL}\left[{ }^{32} \mathrm{P}\right]$ orthophosphoric acid was included in the final volume of washed platelets. The platelet suspensions were incubated for $1 \mathrm{~h}$ at $37^{\circ} \mathrm{C}$, then washed and resuspended at a final concentration of $3 \times 10^{8} / \mathrm{mL}$. Samples of labeled platelets were stimulated with agonists, as above. Aliquots were removed prior to and at 20 and $60 \mathrm{~s}$ after the agonist, added immediately to denaturing solution containing $2 \%$ mercaptoethanol and held at $100^{\circ} \mathrm{C}$ for $3 \mathrm{~min}$. Proteins were separated on a $5-18 \%$ gradient polyacrylamideSDS slab gel. Phosphorylated bands were identified by autoradiogram then cut from the dried gel and solubilized in $80 \%$ Protosol before counting using a Beckman LS 7800 liquid scintillation counter (Beckman Instruments Inc., Fullerton, CA).

Flow cytometry analysis of GP Ia/IIa. Washed platelets were resuspended in $\mathrm{NH}_{4} \mathrm{Cl}-\mathrm{TBS}\left(\mathrm{NaCl} 119 \mathrm{mM}\right.$, Tris $30 \mathrm{mM}, \mathrm{NH}_{4} \mathrm{Cl}$ $500 \mathrm{mM}, \mathrm{pH} 7.4$ ) and then fixed with an equal volume of $2 \%$ paraformaldehyde in $0.2 \mathrm{M}$ cacodylate for $1 \mathrm{~h}$. The fixed platelets were incubated with monoclonal antibody $6 \mathrm{Fl}$ (a gift of Dr. B. S. Coller, Stony Brook, NY) directed against GP Ia/IIa as described elsewhere (17), for $2 \mathrm{~h}$ at $25^{\circ} \mathrm{C}$. Binding was visualized using a biotinylated goat anti-mouse second antibody (HyClone Laboratories, Logan, VT) and fluorescein-avidin (Dimension Lab Inc., Mississauga, Ontario). After each incubation, the platelets were washed three times in TBS $/ 0.1 \%$ BSA. The $300-\mu \mathrm{L}$ aliquots at a final platelet concentration of $4 \times 10^{9} / \mathrm{L}$ were used for analysis. Platelet-associated fluorescence was quantified with an EPICS V flow cytometer (Coulter) equipped with an ArgonIon laser $(400 \mathrm{~mW}, 488 \mathrm{~nm})$. Fluorescence was detected at 525 $\mathrm{nm}$. Platelets were analyzed at a rate of $300 / \mathrm{s}$ and were identified by forward angle and orthogonal light scatter. Single parameter, 255-channel, log integral green fluorescent histograms were obtained, and the negative and positive fluorescent populations were resolved. For each sample, mean fluorescence intensity was obtained by dividing total fluorescence recorded by the number of platelets analyzed $\left(2 \times 10^{4}\right.$ platelets $)(18)$.

Platelet adhesion assay. Platelet adhesion to collagen-coated polystyrene plates was performed by the method of Santoro (19). Washed platelets were resuspended in Tris- $\mathrm{NaCl}(\mathrm{NaCl} 140 \mathrm{mM}$, Tris $50 \mathrm{mM}$, glucose $5 \mathrm{mM}, 0.5 \%$ BSA, $\mathrm{pH} 7.4$ ) before incubation with $\mathrm{Na}^{51} \mathrm{CrO}_{4}(100 \mu \mathrm{Ci} / \mathrm{mL})$ for $1 \mathrm{~h}$ at $37^{\circ} \mathrm{C}$. Platelets were washed and resuspended in Tris- $\mathrm{NaCl}$, containing $2 \mathrm{mM} \mathrm{MgCl}_{2}$ at a final concentration of $2.5 \times 10^{9} / \mathrm{L}$. The $1-\mathrm{mL}$ platelet suspension was added to polystyrene dishes $(35-\mathrm{mm}$ diameter, Falcon Labware, Oxnard, CA) previously coated with $25 \mu \mathrm{g} / \mathrm{mL}$ monomeric collagen. Collagen denatured by heating to $100^{\circ} \mathrm{C}$ for $10 \mathrm{~min}$ was used as control. After incubating for $30 \mathrm{~min}$ at $25^{\circ} \mathrm{C}$, the platelets were removed by aspiration and the plates washed three times. Adherent platelets were removed by incubating the dish twice with $1 \mathrm{~mL}$ of $2 \%$ SDS for $30 \mathrm{~min}$. The extracts were aspirated and pooled for determination of radioactivity by scintillation counting. The radioactivity in each sample was compared with that in $1 \mathrm{~mL}$ of the original platelet suspension to determine the percent of platelets adhering to the collagen.

Assay of inositol phosphates. Washed platelets were resuspended in HBSS containing $\left[{ }^{3} \mathrm{H}\right]$ inositol $(80 \mu \mathrm{Ci} / \mathrm{mL})$ and incubated at $37^{\circ} \mathrm{C}$ for $2 \mathrm{~h}$. The platelets were washed, resuspended in HBSS containing $10 \mathrm{mM} \mathrm{LiCl}$ and incubated for $1 \mathrm{~h}$ before aggregation studies. One min after addition of agonists the reaction was terminated by transferring the platelet suspensions to tubes containing chloroform/methanol/HCl $(100: 200: 2$, vol/ $\mathrm{vol} / \mathrm{vol})$. Water was added to the tubes before centrifugation and the upper phase was removed and diluted. The inositol phosphates in the upper phase were separated on Dowex-1 anion exchange columns by differential elution (20) of inositol phosphate, inositol bisphosphate, and inositol trisphosphate. Radioisotope measurements of these fractions were determined by scintillation counting using a Beckman LS 7800 liquid scintillation counter.

$A A$ release and $T \times B_{2}$ formation. Washed platelets were resuspended in Krebs-Ringers-HEPES buffer containing $\left[{ }^{14} \mathrm{C}\right]-\mathrm{AA}(50$ $\mu \mathrm{Ci} / \mathrm{mL}$ ) and incubated for $2 \mathrm{~h}$. The platelets were then washed and resuspended before aggregation studies. Aliquots of platelets were removed before and $2 \mathrm{~min}$ after the addition of agonist and added immediately to ethyl acetate, agitated, centrifuged, and the organic phase collected. Two further extractions were performed with ethyl acetate, the last after addition of $10 \mu \mathrm{L}$ of 1 $\mathrm{M} \mathrm{HCl}$. The solvent was evaporated under $\mathrm{N}_{2}$, unlabeled AA, and $\mathrm{TxB}_{2}$ were added as standards, and the extracts were resuspended in ethyl acetate. These were applied to Baker Si-250 TLC plates (J. T. Baker Co., Phillipsburg, NJ) that were activated at $100^{\circ} \mathrm{C}$ for $60 \mathrm{~min}(21)$. Lipid migration took place in a solvent system of chloroform:methanol:acetic acid:water (90:8:1:0.8, $\mathrm{vol} / \mathrm{vol} / \mathrm{vol} / \mathrm{vol}$ ) (22). The lipids were localized by brief exposure to iodine vapor and their mobility compared to the standards on the same plate. Radioactivity was measured using a System 200 imaging scanner (Bioscan Inc., Washington, DC) coupled to an IBM-PC-XT. The radioactivity appearing in the AA and $\mathrm{TxB}_{2}$ "peaks" were compared pre- and poststimulation to determine the percent of AA released from the membrane phospholipids and subsequently converted to $\mathrm{TxB}_{2}$.

$\mathrm{TxB}_{2}$ was quantitated by ELISA using specific rabbit antibody to $\mathrm{TxB}_{2}$ as previously described $(14,23)$. Briefly, after aggregation of washed platelets, the suspension was centrifuged and the supernatant removed and diluted in PBS-BSA. Aliquots plus anti- $\mathrm{TxB}_{2}$ were added to wells of microtiter plates, previously coated with $\mathrm{TxB}_{2}-\mathrm{BSA}$ conjugate, and allowed to react for $18 \mathrm{~h}$. The plates were washed and goat anti-rabbit IgG-alkaline phosphatase conjugate was added and after incubation, the plates were washed again before the addition of phosphatase substrate. The absorbance at $405 \mathrm{~nm}$ was read for each well using a microtiter plate reader (Titertek Multiscan, Mississauga, Ontario).

Statistical analysis. Student's $t$ test was used to compare the mean values of the results obtained for adult and neonatal platelets for each study.

\section{RESULTS}

Platelet aggregation. Aggregation was compared in 16 cord blood/adult pairs. All cord blood samples described were from elective term cesarean births, but studies of cord blood from fullterm vaginal births did not show significant differences from our results. Aggregation responses in neonatal platelets and adult 
platelets varied depending on the agonist used. Responses to thrombin and $\mathrm{IP}_{3}$ were similar in the two groups (Fig. $1 A$ ). The response of neonatal platelets to $\mathrm{OAG}$ was moderately reduced compared to adult platelets. The collagen response in neonatal platelets was markedly reduced compared to adult controls both at 1.0 and at $10.0 \mu \mathrm{g} / \mathrm{mL}$.

Serotonin secretion from dense granules. The release of $\left[{ }^{14} \mathrm{C}\right]$ serotonin was studied in 10 cord blood/adult pairs (Fig. $1 B$ ). Secretion induced by thrombin, $\mathrm{OAG}$, and $\mathrm{IP}_{3}$ was not different in neonatal and adult platelets. However, the response to collagen was markedly diminished in the neonatal platelets.

Phosphorylation of platelet proteins. The phosphorylation of MLC and $47 \mathrm{~K}$ is shown in Figure $2 A$ and $B$. For these studies, the calcium ionophore, A23187, was used instead of $\mathrm{IP}_{3}$ to stimulate calcium flux so that all samples could be studied in intact (nonpermeabilized) platelets. Phosphorylation of MLC and $47 \mathrm{~K}$ in unstimulated platelets was not different in the two groups. Baseline phosphorylation of MLC was $146.4 \pm 74.8$ and $161.2 \pm 78.0 \mathrm{cpm} / 4 \times 10^{8}$ platelets for adult and neonatal platelets, respectively. Baseline phosphorylation of $47 \mathrm{~K}$ was $432.0 \pm 124.0 \mathrm{cpm} / 4 \times 10^{8}$ platelets for adult platelets and 381.7 $\pm 116.1 \mathrm{cpm} / 4 \times 10^{8}$ platelets for neonatal platelets. Phosphorylation of MLC and $47 \mathrm{~K}$ in response to thrombin, OAG, and A23187 was similar in neonatal and adult platelets. In contrast, in neonatal platelets, phosphorylation of both MLC and $47 \mathrm{~K}$ was minimal in response to $10.0 \mu \mathrm{g} / \mathrm{mL}$ collagen.

Flow cytometric analysis of GP Ia/IIa $6 \mathrm{~F} 1$ binding was studied in seven neonatal/adult pairs (Fig. $3 A$ and $B$ ). The mean fluorescence intensity for neonatal samples was not different for adult samples (mean channel, 72, for both). Paired samples, studied on the same day, had similar fluorescence intensities, although this value varied between experiments (Fig. $3 B$ ). Of the particles in the platelet of neonatal and adult samples, $80 \%$ and
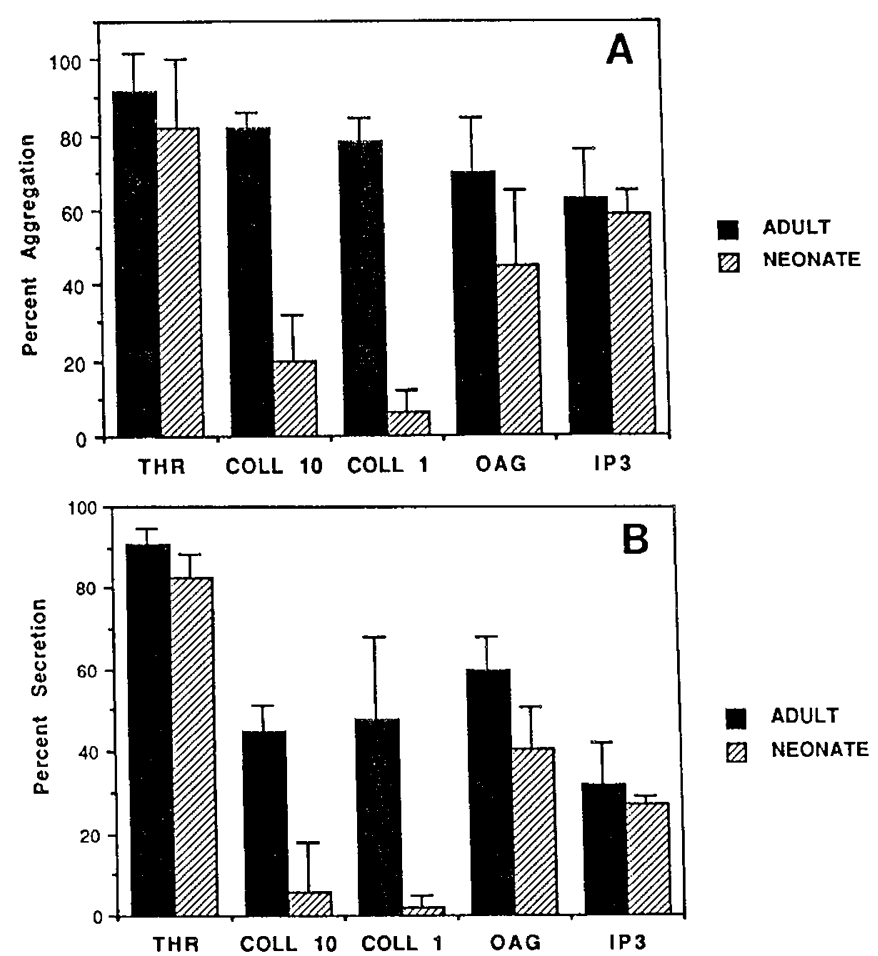

Fig. 1. A, percent maximum aggregation of washed platelet suspensions in response to thrombin $0.2 \mathrm{U} / \mathrm{mL}(T H R)$, collagen $10 \mu \mathrm{g} / \mathrm{mL}$ (COLL 10), collagen $1.0 \mu \mathrm{g} / \mathrm{mL}(C O L L ~ 1), O A G 100 \mu \mathrm{g} / \mathrm{mL}$, and $\mathrm{IP}_{3}$ $10 \mu \mathrm{M}$. Each bar represents the mean $\pm 1 \mathrm{SD}$ of 16 experiments. $B$, percent secretion of $\left[{ }^{14} \mathrm{C}\right]$ serotonin from washed platelet suspensions in response to thrombin $0.2 \mathrm{U} / \mathrm{mL}$ (THR), collagen $10 \mu \mathrm{g} / \mathrm{mL}$ (COLL 10$)$, collagen $1.0 \mu \mathrm{g} / \mathrm{mL}$ (COLL 1 ), OAG $100 \mu \mathrm{g} / \mathrm{mL}$, and $\mathrm{IP}_{3} 10 \mu \mathrm{M}$. Each bar represents the mean $\pm 1 \mathrm{SD}$ of 10 experiments.
$81 \%$, respectively, gave a positive reaction with $6 \mathrm{~F} 1$. This is similar to the $83 \%$ positivity reported by Coller et al. (17) for $6 \mathrm{~F} 1$ binding.

Adhesion of platelets to collagen. Adhesion of platelets to dishes coated with $25 \mu \mathrm{g} / \mathrm{mL}$ of monomeric collagen was determined in the presence of $2 \mathrm{mM} \mathrm{Mg}^{2+}$ for 10 neonate/adult pairs. There was no significant difference in percent adhesion between the neonatal and adult platelets using this assay (Table 1).

Formation of inositol phosphates. Stimulation of platelets with thrombin and collagen resulted in formation of all species of inositol phosphate. In Figure 4, the increase in total inositol phosphates are shown. Neonatal and adult platelet production of inositol phosphates in response to $0.2 \mathrm{U} / \mathrm{mL}$ of thrombin were not significantly different. However, significant differences between adult and neonatal platelets were observed when collagen was used as the agonist. Using $100 \mu \mathrm{g} / \mathrm{mL}$ collagen, there was no further increase in inositol phosphates produced by adult platelets compared to the response to $10 \mu \mathrm{g} / \mathrm{mL}$. The neonatal platelets did produce inositol phosphates at $100 \mu \mathrm{g} / \mathrm{mL}$ of collagen, but the response was still significantly less than that of the adult control. The relative production of inositol mono-, bis-, and trisphosphate formed were not different in adult and neonatal platelets.

AA release and TX formation. Release of $\left[{ }^{14} \mathrm{C}\right]$-AA from platelet phospholipids is shown in Figure 5. In response to thrombin, neonatal platelets released more AA $(29.5 \pm 3.2 \%)$ than adult platelets $(19.6 \pm 1.8 \%)$. However, in response to collagen, neonatal platelets released significantly less AA.

Identification of labeled $\mathrm{TxB}_{2}$ separated by thin-layer chromatography allowed determination of the percent of released $A A$ that was subsequently converted to $T \times B_{2}$. The conversion of $A A$ to $\mathrm{TxB}_{2}$ was less in the neonatal platelets regardless of whether the stimulus was thrombin or collagen (Table 2). Quantitation of $\mathrm{TxB}_{2}$ production by ELISA, however, showed no difference in the absolute amount of $\mathrm{TxB}_{2}$ produced in response to thrombin. In contrast, neonatal platelets did produce less $\mathrm{TxB}_{2}$ in response to collagen.

\section{DISCUSSION}

We have evaluated the collagen-stimulated activation pathway in neonatal platelets. Because previous investigators have identified a defect in dense granule secretion of ADP and serotonin, we began our studies by looking at the secretion and aggregation responses of neonatal platelets to two physiologic agonists, thrombin and collagen. From these initial studies, it became clear that there was a differential response of neonatal platelets to thrombin and collagen. The response to thrombin did not differ from the platelets of adult controls, but the response to collagen even at relatively high concentrations was minimal. Therefore, we investigated aspects of the activation pathway that leads to dense granule secretion to determine whether these are deficient in the neonatal platelet, particularly when collagen is the activation stimulus.

Two separable processes contribute synergistically to secretion. These complementary processes, granule centralization and granule membrane fusion are each the end result of two separate pathways that are activated by products of phospholipase $C$ mediated hydrolysis of $\mathrm{PIP}_{2}$. These second messengers are IP that releases calcium from intracellular stores $(14,24)$ and diacylglycerol that activates a calcium and phospholipid-dependent kinase, protein kinase $\mathrm{C} \mathrm{(25).} \mathrm{The} \mathrm{increase} \mathrm{in} \mathrm{cytosolic} \mathrm{calcium}$ activates a calcium/calmodulin-dependent MLC kinase that phosphorylates MLC. This promotes interaction of myosin with actin filaments, contraction of the actin-myosin cytoskeleton $(26,27)$ and centralization of granules. Protein kinase $C$ phosphorylates proteins thought to be associated with the fusion of granular membranes with those of the open canalicular system, the internal membrane channels of the platelet that are in continuity with the plasma membrane (28). Phosphorylation of 


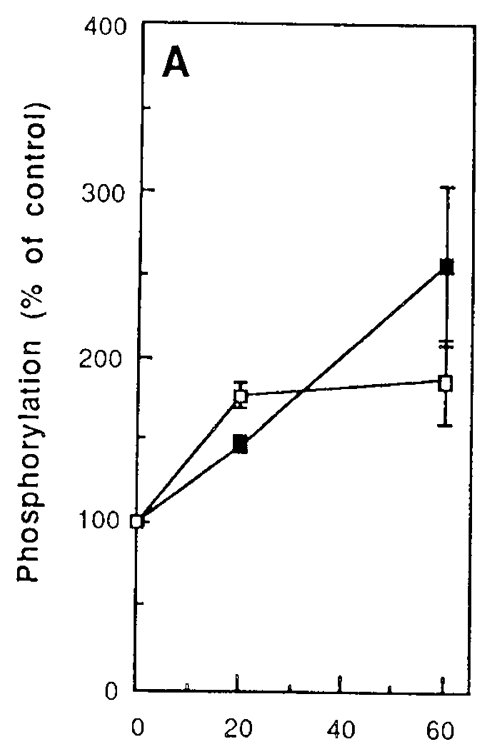

THR

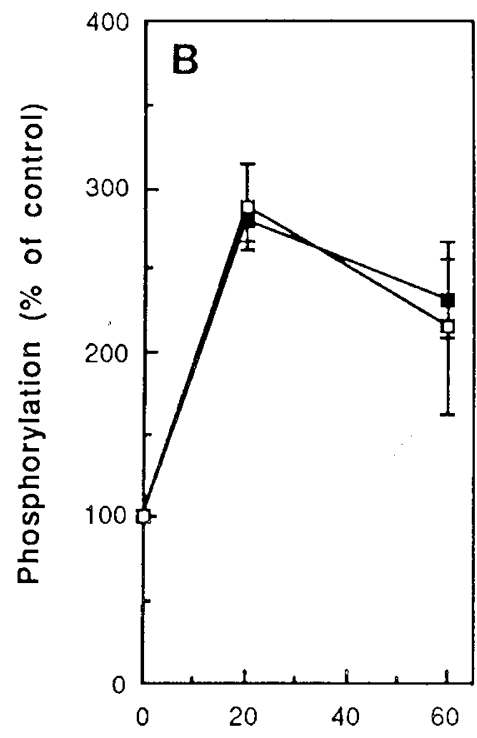

THR
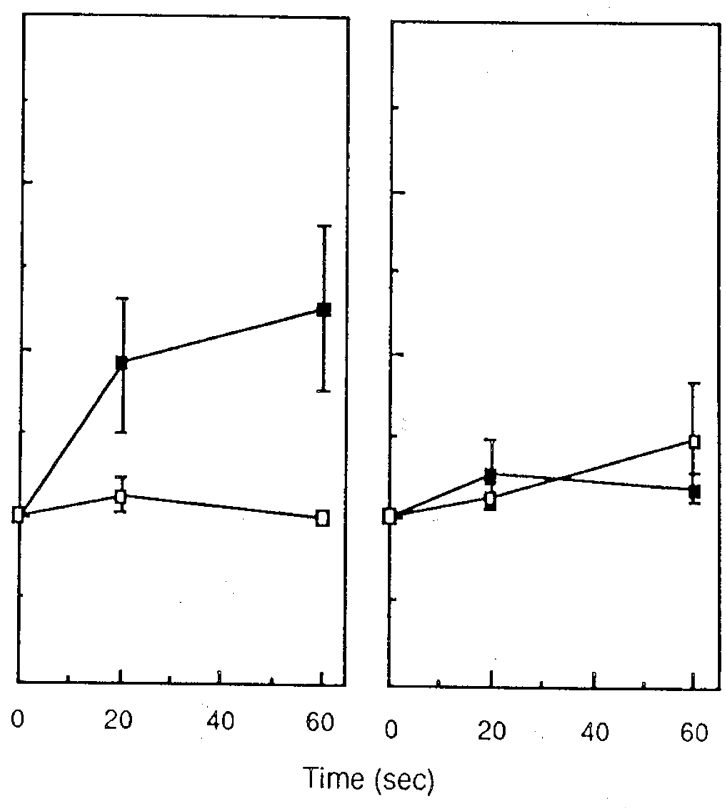

OAG

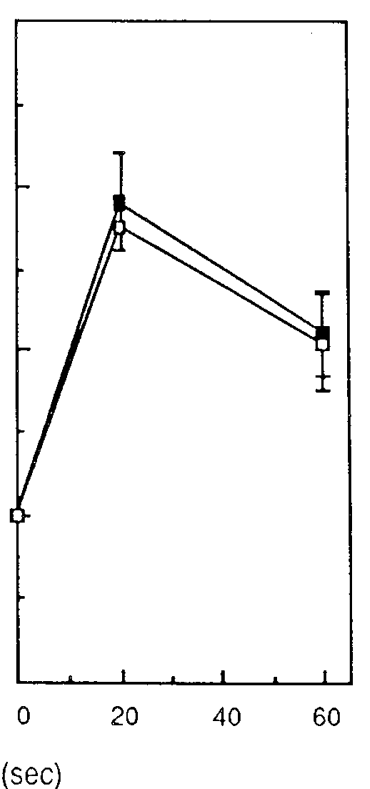

OAG

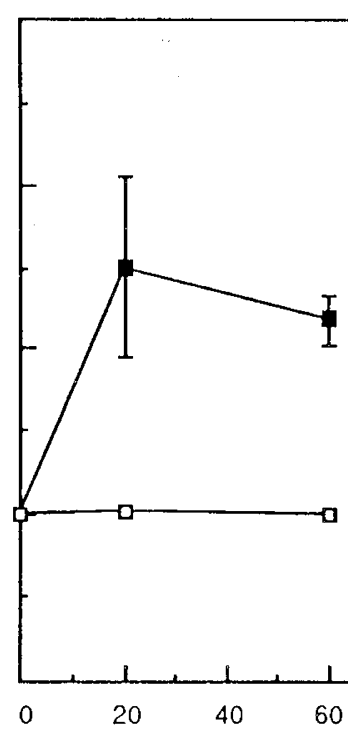

Time (sec)

COLL

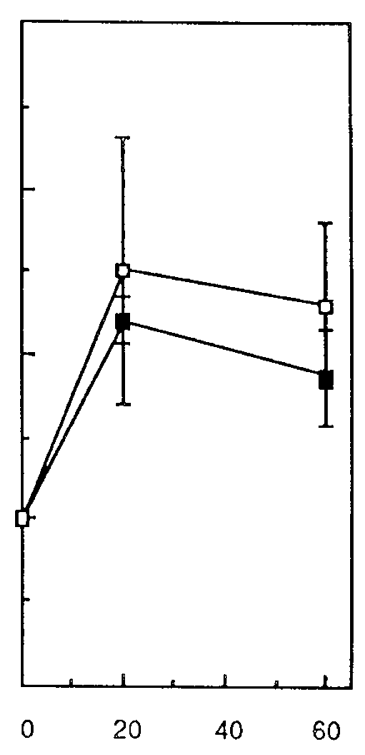

A23187

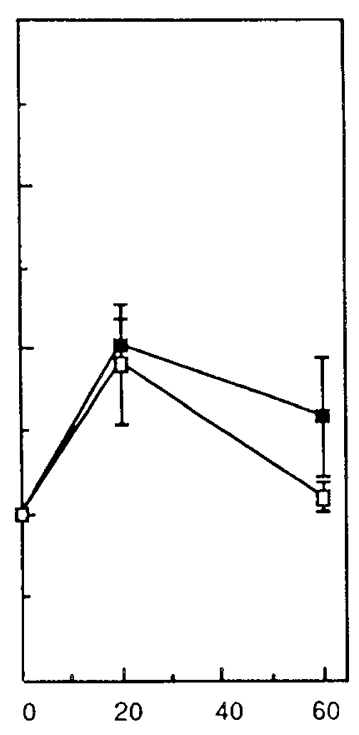

A23187

Fig. 2. A, phosphorylation of myosin light chain in washed platelets stimulated by thrombin $0.2 \mathrm{U} / \mathrm{mL}(T H R)$, collagen $10 \mu \mathrm{g} / \mathrm{mL}(C O L L)$, OAG $100 \mu \mathrm{g} / \mathrm{mL}$, and A231874 $\mu \mathrm{M}$. Closed symbols represent adult platelets and open symbols represent neonatal platelets. Each point is the mean $\pm 1 \mathrm{SE}$ of four experiments. $B$, phosphorylation of the $47000 \mathrm{D}$ protein in washed platelets stimulated by thrombin $0.2 \mathrm{U} / \mathrm{mL}$ (THR), collagen 10 $\mu \mathrm{g} / \mathrm{mL}(C O L L), \mathrm{OAG} 100 \mu \mathrm{g} / \mathrm{mL}$, and A23187 $4 \mu \mathrm{M}$. Closed symbols represent adult platelets and open symbols represent neonatal platelets. Each point is the mean $\pm 1 \mathrm{SE}$ of four experiments.

$47 \mathrm{~K}$, a specific substrate of protein kinase $\mathrm{C}$, can be used as a marker of enzyme activation. It is these two separate but complementary processes, granule centralization and granule membrane fusion, that together result in granule secretion (28).

Using selective stimuli of either calcium flux ( $\mathrm{IP}_{3}$ and the calcium ionophore A23187) (14) or protein kinase $C$ activation (the synthetic diglyceride, OAG) (29), we examined these two processes separately to identify potential differences in the secretion response of neonatal and adult platelets.

The calcium-dependent processes, as stimulated either by A23187 or by addition of $\mathrm{IP}_{3}$ to permeabilized platelets, did not differ in neonatal and adult platelets. MLC phosphorylation, in particular, was not deficient in the cord blood platelets. The protein kinase C-dependent pathways also appeared intact, because OAG-induced secretion and $47 \mathrm{~K}$ phosphorylation were present. We therefore examined early activation steps that lie upstream from the bifurcation of the calcium-dependent and protein kinase C-dependent pathways, specifically those related to collagen activation.

Collagen binds to specific surface membrane receptors and although there has been some controversy over identification of the specific protein involved, recent evidence supports the role of GP Ia/IIa as a receptor that mediates $\mathrm{Mg}^{2+}$-dependent collagen binding $(17,30)$. Rare patients with an absent response to collagen have been shown to lack these glycoproteins on their platelet surface $(31,32)$. Using $6 \mathrm{~F} 1$, a MAb that recognizes GP 

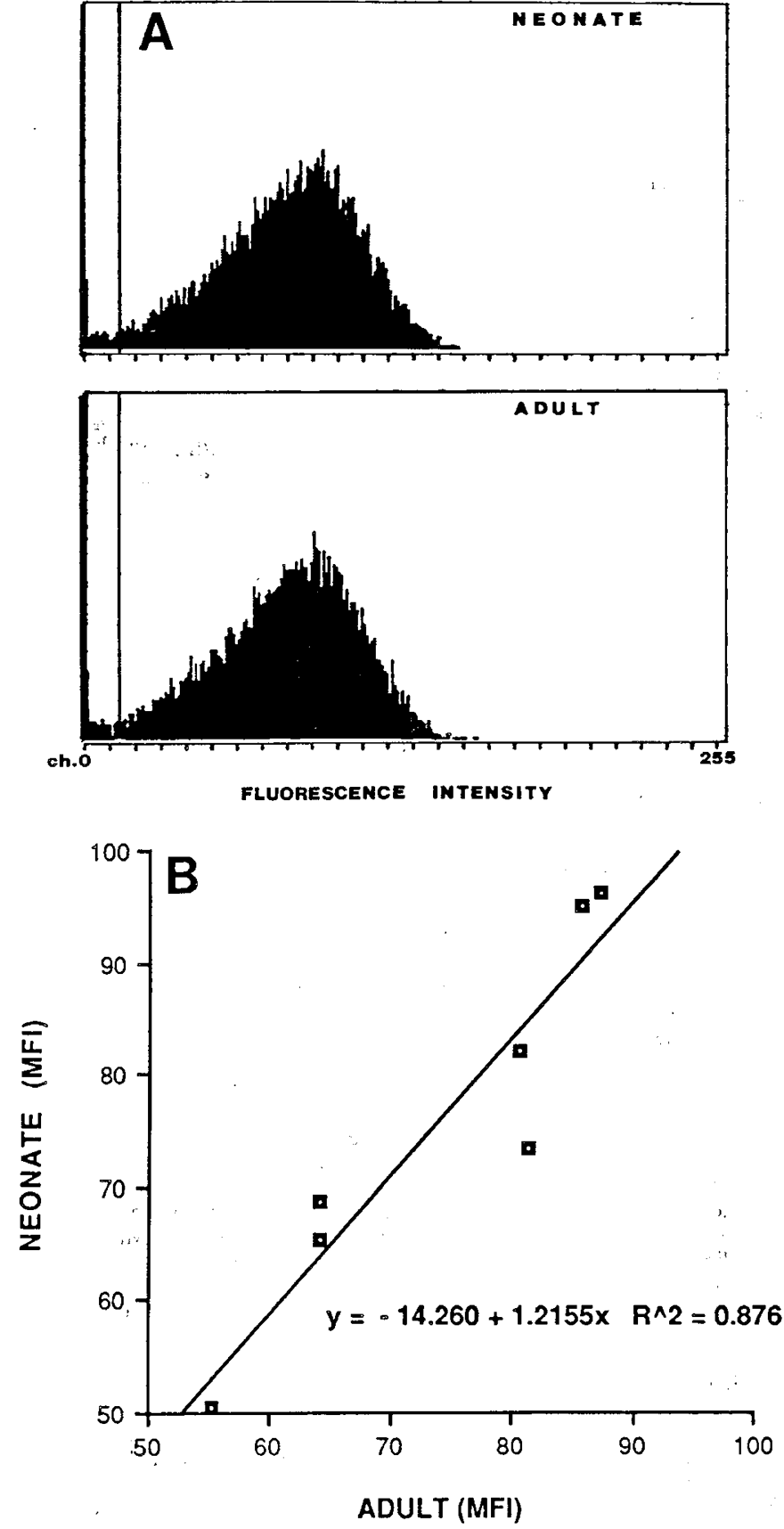

Fig. 3. Flow cytometric analysis of $6 \mathrm{~F} 1$ binding to adult and neonatal platelets. $A$; representative histograms of fluorescence recorded after binding of $6 \mathrm{~F} 1$, biotinylated second antibody, and fluorescein-avidin to platelets of a neonate and an adult control. The vertical line separates negative and positive fluorescent populations. For each sample, $2 \times 10^{4}$ cells were counted. A three-decade log scale was used. $B$, each point represents the mean fluorescence intensities $(M F I)$ recorded for each of seven adult/neonatal pairs after binding of $6 \mathrm{~F} 1$, biotinylated second antibody, and fluorescein-avidin.

Table 1. Adhesion of neonatal and adult platelets to collagen

\begin{tabular}{lcl}
\hline \multirow{2}{*}{ Collagen substrate } & \multicolumn{2}{c}{$\%$ Adhesion } \\
\cline { 2 - 3 } \multicolumn{1}{c}{ Adult } & \multicolumn{1}{c}{ Neonate } \\
\hline Monomeric $(25 \mu \mathrm{g} / \mathrm{mL})$ & $18.6 \pm 9.3^{*}$ & $20.1 \pm 11.6(\mathrm{NS})$ \\
Denatured $(25 \mu \mathrm{g} / \mathrm{mL})$ & $6.0 \pm 2.1$ & $10.1 \pm 3.3(\mathrm{NS})$ \\
\hline
\end{tabular}

* Mean $\pm 1 \mathrm{SD}$ of 10 experiments.

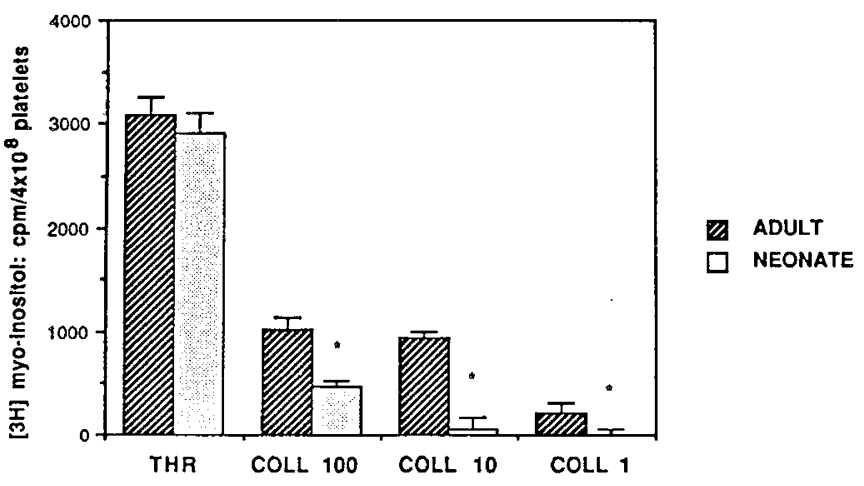

Fig. 4. Increase in total inositol phosphates in response to thrombin $0.2 \mathrm{U} / \mathrm{mL}($ THR), and collagen, $100 \mu \mathrm{g} / \mathrm{mL}$ (COLL 100$), 10 \mu \mathrm{g} / \mathrm{mL}$ $($ COLL 10$), 1 \mu \mathrm{g} / \mathrm{mL}$ (COLL 1 ), over unstimulated controls $(3162 \pm$ $68.5 \mathrm{cpm}$ ). Each bar represents the mean $\pm \mathrm{SE}$ of six experiments. The asterisk identifies a difference between the adult and neonatal means significant at $p<0.05$.

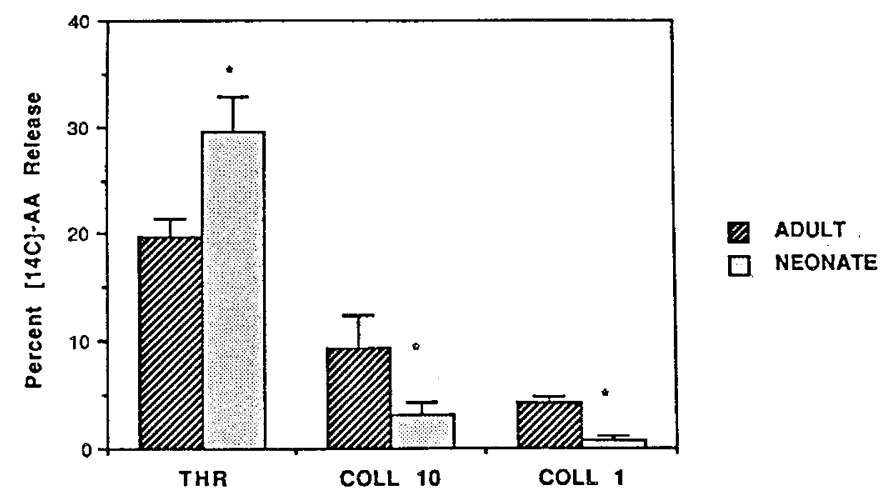

Fig. 5. Percent release of $\left[{ }^{14} \mathrm{C}\right]$-AA from platelet membrane phospholipids in adult and neonate in response to thrombin $0.2 \mathrm{U} / \mathrm{mL}($ THR $)$ and collagen, $10 \mu \mathrm{g} / \mathrm{mL}$ (COLL 10), $1 \mu \mathrm{g} / \mathrm{mL}$ (COLL 1). Each bar represents the mean $\pm \mathrm{SE}$ of seven experiments. The asterisk identifies a difference between the adult and neonatal means significant at $p<$ 0.05 .

Ia/IIa, we used flow cytometry to compare the binding of this antibody to adult and neonatal platelets. We did not find differences either in the percent of cells that bound $6 \mathrm{~F} 1$ or the mean fluorescence intensity, which reflects the relative number of binding sites per cell. This suggests that the Ia/IIa complex is present on neonatal platelets in comparable number to those present on adult platelets. The possibility of decreased numbers of collagen receptors was considered a significant possibility since the number of $\alpha$-adrenergic receptors on neonatal platelets is markedly decreased, accounting for their minimal response to epinephrine (33). This appears to be an isolated receptor deficiency because the amounts of GP IIb/IIIa and GP Ib have been reported to be normal on the surface of fetal platelets (18).

As we had already demonstrated minimal aggregation and secretion responses to collagen, we also evaluated the function of this collagen receptor using an adhesion assay that was not dependent on activation of the platelet. The adhesion of $\left[{ }^{51} \mathrm{Cr}\right]$ labeled neonatal platelets to monomeric collagen was not different from adult samples.

In view of these findings, we proceeded to evaluate early steps in the stimulus-response pathway of collagen. The platelets' response to collagen involves both phospholipase $\mathrm{C}$-mediated phosphatidylinositol hydrolysis and phospholipase $\mathrm{A}_{2}$-mediated release of AA from membrane phospholipids and subsequent formation of $\mathrm{TxA}_{2}(34,35)$. Although it is known that both phospholipase $\mathrm{C}$ and phospholipase $\mathrm{A}_{2}$-mediated pathways are involved, it is unclear whether they are activated sequentially or simultaneously. Pollock et al. (36) have demonstrated that col- 
Table 2. $T x B_{2}$ production in neonatal and adult platelets

\begin{tabular}{|c|c|c|c|c|}
\hline \multirow[b]{2}{*}{ Agonist } & \multicolumn{2}{|c|}{$\%$ AA converted to $\mathrm{TxB}_{2}$} & \multicolumn{2}{|c|}{ Quantity $\mathrm{TxB}_{2}$ produced $(\mathrm{ng} / \mathrm{mL})$} \\
\hline & Adult & Neonate & Adult & Neonate \\
\hline Thrombin $0.2 \mathrm{U} / \mathrm{mL}$ & $17 \pm 3^{*}$ & $11 \pm 4$ & $382.5 \pm 101.5 \dagger$ & $319.0 \pm 93.4(\mathrm{NS})$ \\
\hline Collagen $10 \mu \mathrm{g} / \mathrm{mL}$ & $15 \pm 4$ & $10 \pm 2$ & $101.4 \pm 18.7$ & $52.7 \pm 12.6(p<0.05)$ \\
\hline
\end{tabular}

$*$ Mean $\pm 1 \mathrm{SD}$ of seven experiments.

$\dagger$ Mean $\pm 1 \mathrm{SE}$ of eight experiments.

lagen can stimulate AA release without an increase in cytoplasmic calcium, suggesting that the $\mathrm{AA} / \mathrm{TxA}_{2}$ pathway may be the initial activation pathway with subsequent phosphoinositide hydrolysis. Considering this, we evaluated the activity of both phospholipase $\mathrm{A}_{2}$ and $\mathrm{C}$ in neonatal platelets.

Phosphoinositide hydrolysis was measured by labeling platelets with $\left[{ }^{3} \mathrm{H}\right]$ inositol and stimulating them with thrombin and increasing concentrations of collagen $(1-100 \mu \mathrm{g} / \mathrm{mL})$. In response to thrombin, neonatal platelet phosphoinositide hydrolysis was normal but the response to collagen was markedly decreased although some hydrolysis occurred at the highest collagen concentration $(100 \mu \mathrm{g} / \mathrm{mL})$ used. In contrast, the response of adult platelets to $10 \mu \mathrm{g} / \mathrm{mL}$ collagen versus $100 \mu \mathrm{g} / \mathrm{mL}$ collagen did not differ suggesting that a maximal response had been achieved in the adult platelets at the $10 \mu \mathrm{g} / \mathrm{mL}$ concentration. Phospholipase $\mathrm{C}$ activity appears to be normal in the neonatal platelet, but activation of this enzyme by collagen is decreased.

Inasmuch as $\operatorname{TxA}_{2}$ production is an important intermediate in collagen activation and acts as a second messenger to further activate phospholipase $C$, we investigated the production of $\mathrm{TxA}_{2}$ in neonatal platelets. Stuart and Allen (37) and Stuart et al. (38) have identified some differences in $\mathrm{AA}$ release and $\mathrm{TxA}_{2}$ synthesis between adult and neonatal platelets. In response to maximal stimulation by thrombin, neonatal platelet membranes release more AA than those of the adult. There is also more free AA available in neonatal plasma to provide substrate for $\mathrm{TxA}_{2}$ synthesis. Although the fraction of AA converted to TxA $\mathrm{A}_{2}$ was less in the neonatal platelet, probably because of decreased activity of cyclooxygenase, the absolute amounts produced were comparable to those in the adult platelet. We found a similar pattern of response to thrombin with increased AA release from the neonatal platelets even in response to the lower dosage of thrombin used in our study $(0.2$ versus $5 \mathrm{U} / \mathrm{mL})$. $\mathrm{TxB}_{2}$ production measured by ELISA was the same for adult and neonate. In contrast, collagen stimulated less AA release from neonatal platelets than from adult platelets and as a result, less AA is available for conversion to thromboxane. In response to $10 \mu \mathrm{g} / \mathrm{mL}$ of collagen, $\mathrm{TxB}_{2}$ production was also significantly decreased in neonatal platelets. These studies were done in washed platelets and the difference may not be present if studies are done in neonatal plasma where more free AA may be available for conversion to $\mathrm{TxA}_{2}$. These results do suggest that collagen activation of phospholipase $A_{2}$ is decreased in the neonatal platelet.

It is unclear from these studies whether activation of phospholipase $\mathrm{A}_{2}$ and $\mathrm{C}$ are both deficient in response to collagen or whether the present findings may be the result of a specific deficiency in activation of phospholipase $\mathrm{A}_{2}$ only, with the decreased activation of phospholipase $\mathrm{C}$ due to decreased $\mathrm{TxA}_{2}$ production. A defect in activation of phospholipase $A_{2}$, specifically, would explain the differential response of neonatal platelets to thrombin and collagen, as phospholipase $A_{2}$ appears to be more critical in the response to collagen.

Recent studies by Saxena et al. (39) have identified a role for intracellular histamine as a second messenger in platelets stimulated with collagen. Their studies have demonstrated that collagen-induced platelet aggregation, secretion, and thromboxane synthesis can be inhibited by inhibition of histamine synthesis or antagonism of histamine binding to its intracellular receptor. This inhibition can be overcome in permeabilized platelets by addition of exogenous histamine suggesting that histamine plays a role in collagen-stimulated activation at the level of thromboxane generation. These studies identify a mechanism that could contribute to decreased phospholipase $\mathrm{A}_{2}$ activation in neonatal platelets but also illustrate that the coupling of receptor to enzyme is still not completely understood and there may be other intermediate steps that are responsible for the deficient response to collagen in neonatal platelets.

Acknowledgments. The authors acknowledge Dr. B. S. Coller for the kind gift of 6F1, Dr. E. Rector for expert assistance with flow cytometry analysis, and the staff of the Labour Suite at the Health Sciences Centre for aid in collecting cord blood samples.

\section{REFERENCES}

1. Buchanan GR 1978 Neonatal coagulation: normal physiology and pathophysiology. Clin Haematol 7:85-109

2. Creter D, Goldman JA, Djaldetti M 1977 The fibrinolytic pathway in the human fetus. Biol Neonate 32:94-96

3. Mull MM, Hathaway WE 1970 Altered platelet function in newborns. Pediatr Res 4:229-237

4. Corby DG, Schulman I 1971 The effects of antenatal drug administration on platelets of newborn infants. J Pediatr 79:307-313

5. Corby DG, Zuck TF 1976 Newborn platelet dysfunction: a storage pool and release defect. Thromb Haemost 36:200-207

6. Whaun JM 1973 The platelet of the newborn infant. Thromb Diathes Hemorrh 30:327-333

7. Ts'ao C-H, Green D, Schultz K 1976 Function and ultrastructure of platelets of neonates. Br J Haematol 32:225-233

8. Holmsen H, Weiss HJ 1970 Hereditary defect in the release reaction caused by a deficiency in the storage pool of platelet adenine nucleotides. $\mathrm{Br} \mathrm{J}$ Haematol 19:643-649

9. Rao AK, Kolke K, Willis J, Daniel JL, Beckett C, Hassel B, Day HJ, Smith JB, Holmsen $\mathrm{H} 1984$ A platelet secretion defect associated with impaired liberation of arachidonic acid and normal myosin light chain phosphorylation. Blood 64:914-921

10. Wu KK, Minkoff IM, Rossi EC, Chen Y-C 1981 Hereditary bleeding disorder due to primary defect in the platelet release reaction. Br J Haematol 47:241249

11. Gerrard JM 1982 Platelet aggregation and the influence of prostaglandins. Methods Enzymol 86:642-654

12. Cazenave JP, Packham MA, Mustard FJ 1973 Adherence of platelets to a collagen coated surface: development of a quantitative method. J Clin Lab Med 82:978-990

13. Wakasugi H, Kimura T, Haase W, Kribben A, Kaufmann R, Schulz I 1982 Calcium uptake into acini from rat pancreas: evidence for intracellular ATPdependent calcium sequestration. J Membr Biol 65:205-220

14. Israels SJ, Robinson R, Docherty JC, Gerrard JM 1985 Activation of permeabilized by platelets by inositol-1,4,5-trisphosphate. Thromb Res 40:499509

15. Jerushalmy Z, Zucker MB 1966 Some effects of fibrinogen degradation products on blood platelets. Thromb Diath Heamorrh 15:413-419

16. Gerrard JM, Carroll RC 1981 Stimulation of platelet protein phosphorylation by arachidonic acid and endoperoxide analogs. Prostaglandins 22:81-94

17. Coller BS, Beer JH, Scudder LE, Steinberg MH 1989 Collagen-platelet interactions: Evidence for a direct interaction of collagen with platelet GP Ia/IIa and an indirect interaction with platelet GP IIb/IIIa mediated by adhesive proteins. Blood 74:182-192

18. Gruel Y, Boizard B, Daffos F, Forestier F, Caen J, Wautier JL 1986 Determination of platelet antigens and glycoproteins in the human fetus. Blood 68:488-492

19. Santoro SA 1986 Identification of a 160,000 dalton platelet membrane protein that mediates the initial divalent cation-dependent adhesion of platelets to collagen. Cell 46:913-920

20. Israels SJ, Gerrard JM, Robinson P 1986 Differential effects of spermine on aggregation, inositol phosphate formation and protein phosphorylation in human platelets in response to thrombin, arachidonic acid, and lysophosphatidic acid. Biochim Biophys Acta 883:247-252

21. Beenken SW, Batra JK, Gerrard JM, Goldenberg GJ 1988 Growth-promoting activity of desmopressin in murine leukemia cells treated in vitro. Cancer Res 48:7055-7059 
22. Salmon JA, Flower RJ 1982 Extraction and thin-layer chromatography of arachidonic acid metabolites. In: Lands WEM, Smith WL (eds) Methods in Enzymology, Vol 86. Academic Press, New York, pp 477-493

23. Docherty JC, Gerrard JM 1986 An enzyme-linked immunosorbent assay for 6-keto PGF Pr. $_{1 \times}$ Prostaglandins 31:375-383

24. Brass LF, Shaller CC, Belmonte EJ 1987 Inositol 1,4,5-tris-phosphate-induced granule secretion in platelets. J Clin Invest 79:1269-1275

25. Nishizuka $Y 1984$ The role of protein kinase $C$ in cell surface signal transduction and tumor promotion. Nature 308:693-698

26. Dabrowska R, Hartshorne DJ $1978 \mathrm{Ca}^{2+}$ and modulator-dependent myosin light chain kinase from non-muscle cells. Biochem Biophys Res Commun 85:1352-1359

27. Hathaway DR, Adelstein RS 1979 Human platelet myosin light chain kinase requires the calcium-binding protein calmodulin for activity. Proc Natl Acad Sci USA 76:1643-1657

28. Gerrard JM, Israels SJ, Friesen LL 1985 Protein phosphorylation and platelet secretion. Nouv Rev Fr Hematol 27:267-273

29. Friesen LL, Gerrard JM 1985 The effects of 1-oleoyl-2-acetyl glycerol on platelet protein phosphorylation. Am J Pathol 121:79-87

30. Santoro SA, Rajpara SM, Staatz WD, Woods Jr VL 1988 Isolation and characterization of a platelet surface collagen binding complex related to VLA-2. Biochem Biophys Res Commun 153:217-223

31. Nieuwenhuis HK, Akkerman JWN, Houdijk WP, Sixma JJ 1985 Human blood platelets showing no response to collagen fail to express surface glycoprotein Ia. Nature 318:470-472
32. Kehrel B, Balleisen L, Kokott R, Mesters R, Stenzinger W, Clemetson KJ, van de Loo J 1988 Deficiency of intact thrombospondin and membrane glycoprotein Ia in platelets with defective collagen-induced aggregation and spontaneous loss of disorder. Blood 71:1074-1078

33. Corby DG, O'Barr TP 1981 Decreased alpha-adrenergic receptors in newborn platelets: Cause of abnormal response to epinephrine. Dev Pharmacol 2:215225

34. Rittenhouse SE, Allen CL 1982 Synergistic activation by collagen and 15hydroxy-9 $\alpha$-1 $1 \alpha$-peroxidoprosta-5, 13-dienoic acid $\left(\mathrm{PGH}_{2}\right)$ of phosphatidylinositol metabolism and arachidonic acid release in human platelets. $\mathrm{J}$ Clin Invest 70:1216-1224

35. Siess W, Cuatrecasas P, Lapetina EG 1983 A role for cyclooxygenase products in the formation of phosphatidic acid in stimulated platelets. $J$ Biol Chem 258:4683-4686

36. Pollock WK, Rink TJ, Irvine RF 1986 Liberation of $\left[{ }^{3} \mathrm{H}\right]$ archidonic acid and changes in cytosolic free calcium in fura-2-loaded human platelets stimulated by ionomycin and collagen. Biochem J 235:869-877

37. Stuart MJ, Allen JB 1982 Arachidonic acid metabolism in the neonatal platelet. Pediatrics 69:714-718

38. Stuart MJ, Dusse J, Clark DA, Walenga RW 1984 Differences in thromboxane production between neonatal and adult platelets in response to arachidonic acid and epinephrine. Pediatr Res 18:823-826

39. Saxena SP, McNicol A, Brandes LJ, Becker AB, Gerrard JM 1990 A role for intracellular histamine in collagen-induced platelet aggregation. Blood 75:407-414 